\title{
LA CORRESPONDENCIA DIPLOMÁTICA DEL CONDE DE FUENTES EN TORNO AL CONFLICTO JESUÍTICO
}

\author{
Miguel BELLOD LÓPEZ \\ Universidad de Alicante
}

\begin{abstract}
Resumen
Entre 1767 y 1772 el conde de Fuentes, desde su cargo de embajador en Francia, participó en la consecución de algunos objetivos que, tras la expulsión de la Compañía de Jesús de España, se fueron perfilando con el necesario apoyo de la corte de Versalles. El presente artículo repasa estas acciones a través de la correspondencia diplomática de Joaquín Pignatelli, un trabajo imbuido de las condiciones personales y familiares que rodearon su gestión.
\end{abstract}

\begin{abstract}
Between 1767 and 1772 the count of Fuentes, leaning on his office as ambassador in France and with the necessary support of the court of Versailles, played a major role in the realization of certain objectives which, as a result of the expulsion of the Society of Jesus from Spain, would took a more defined shape. This paper analises these developments through Joaquín Pignatelli's diplomatic correspondence, whose career was highly influenced by his personal and family circumstances.
\end{abstract}

El 26 de febrero de 1764 Juan Joaquín Atanasio Pignatelli, conde de Fuentes, presentaba sus cartas credenciales a Luis XV e iniciaba una labor diplomática como embajador de España en París que se extendería hasta septiembre de $1772^{\prime}$. De ese lapso temporal hemos estudiado su trabajo una vez que las cortes borbónicas expulsaron de sus fronteras a los jesuitas y se decidieron a solicitar con premura la extinción de la Compañía de Jesús. España y Francia, junto a Nápoles, fueron los Estados que abogaron con mayor insistencia por la confirmación de este hecho, y la gestión de

1. Archivo Histórico Nacional (en adelante A.H.N.), Estado, leg. 6549, «Relación de los primeros pasos del Señor Embajador Conde de Fuentes a su llegada a París el 21 de febrero de I764». Un mes antes había partido desde Madrid. 
Pignatelli se centró en dos aspectos básicos: lograr el consentimiento de Francia para ubicar a los expulsos procedentes de España en la isla de Córcega -tras la negativa de Clemente XIII a recibirlos en sus dominios-, y coordinar los esfuerzos que la política carlotercerista debía practicar junto a la corte gala para la total desaparición de la $\mathrm{Re}$ ligión de San Ignacio.

Tres años antes de su llegada a Francia, España había signado con la nación vecina el Tercer Pacto de Familia, evidencia del deseo por defender unos intereses comunes y muestra de la relevancia que el puesto de embajador en París representaba. Sorprende, por tanto, las pocas cualidades que los coetáneos del conde de Fuentes otorgaban a su persona para la ostentación de tal dignidad ${ }^{2}$, a pesar de una trayectoria política considerable: en 1754 había sido nombrado embajador en la corte de Turín, puesto que desempeñó hasta su traslado a la embajada española en Londres en 1760; dos años más tarde, y debido a la ruptura de relaciones diplomáticas con Inglaterra, abandonó el cargo, no pasando demasiado tiempo en la reserva, pues en octubre de 1763 se requirieron sus servicios en Francia. Debemos presuponer que los motivos que hacían del conde una persona menos apropiada para la vacante en cuestión no se centraban en sus capacidades, más bien en su conocida filiación projesuita que, desde que los acontecimientos se tornaron negativos para los ignacianos, intentó disimular ${ }^{3}$.

Esta circunstancia nos aporta una nota de interés en el análisis de su cometido, encaminado a cumplir unas directrices que eran contrarias a una institución que su linaje, como muchos otros antes de la repulsa de Carlos III, había apoyado, además de contar con sus dos hermanos menores, José y Nicolás Pignatelli, profesando en dicha corporación. Ello le ocasionará más de un momento de inquietud, preocupado como estaba por el mantenimiento de su reputación y buen crédito, y sin duda colaboró en el proceso que terminó por perturbar las facultades mentales del conde. Ya entre septiembre y octubre de 1764, Fuentes dio señales de su quebradiza salud, tal como constató Fernando de Magallón, secretario de la embajada en Francia, en los correos que remitía al secretario de Estado, Jerónimo Grimaldi. El embajador tuvo que ser sangrado varias veces «de dictamen de los tres Médicos que le asisten [...]. Se confir-

2. DANVILA Y COLladO, M., Reinado de Carlos III, 6 vols., Madrid, 1890-1896, t. II, p. 237: Carlos Ill escribió a Bernardo Tanucci, comunicándole al napolitano que la asignación de la representación española en Francia a Fuentes la había hecho «por falta de sujetos». Igualmente, cuando Joaquín Pignateli c cupó el puesto de embajador en Londres y tuvo que demandar una solución a los ingleses por los problemas que el contrabando ocasionaba en la costa de Yucatán y Honduras, el primer ministro francés, el duque de Choiseul, tampoco confiaba en la negociación: «Me atrevo a predecir [sentenciaba el duque] que la misión del Sr. de Fuentes no producirá ningún efecto que conduzca a la paz bajo la mediación de España. Conozco personalmente a este Embajador y le tengo por uno de los hombres más honestos, pero el más incapaz de misión semejante»; en PALACIO ATARD, V., Las embajadas de Abreu y Fuentes en Londres, 1754-1761, Valladolid, 1950, p. 42.

3. El espiritu de D. José Nicolás de Azara, descubierto en su correspondencia epistolar con don Manuel de Roda, Madrid, 1846, t. I., p. 183: El Agente de Preces escribió desde Roma, el 15 de diciembre de 1768: «Tiene vd. razón en decir que el conde de Fuentes pierde la chaveta, cuando se le toca la tecla de los jesuitas: yo lo experimento cada correo; mis cartas no le llevan más que excomuniones contra ellos; y es un gusto ver sus repuestas, que ni en una tan sola, se atreve á contestarme la especie». 
man los mismos Médicos en que la enfermedad es un efecto de la hipocondría y que se reduce a una grande hinchazón del hígado» ${ }^{4}$. A falta de diagnósticos más precisos, la «hipocondría» del conde pareció ser la causa de sus males, y a punto estuvo de costarle la vida, ya que, según Magallón, «el mal se ha aumentado de manera que ha sido preciso sangrarlo tres veces más, y viendo que ni aun con estas nuevas sangrías tenía alivio, se le ha administrado el viático esta mañana, habiéndolo pedido ayer el enfermo" ". Mas la salud de Fuentes fue recobrándose, recomendando la prescripción médica descanso y ausencia de preocupaciones: «será larga la convalecencia, y le han mandado los Médicos que no piense en escribir, en hablar de negocios ni en cosa alguna que le pueda molestar la cabeza» ${ }^{6}$.

Sin embargo, no pocas preocupaciones le supondrá el decreto de expulsión firmado por Carlos III el 27 de febrero de 1767. La enfermedad del conde a la que hemos aludido le posibilitó gozar de un permiso extraordinario para reponerse en España, de ahí que asistamos a su presencia en la Junta de Estado que se formó a raíz de los motines de la primavera de 1766, sucesos en los que se quiso ver a los jesuitas como instigadores ${ }^{7}$. El embajador francés en Madrid, Pierre Paul d'Ossun, relató a su superior, el duque de Choiseul, «que se avían visto los jesuitas disfrazados de capa, y sombrero redondo con los del tumulto animándolos, y conduciéndolos: que S.M. le avía dicho que todos le avían aconsejado la precisión de tomar esta providencia [la expulsión], aun los que eran apasionados a los mismos jesuitas». El conde de Fuentes recibió estas noticias remitidas desde Madrid con «consternación» y «horror» debido al fin último de la revuelta madrileña, que no era otro que el de «exterminar la misma Persona, y toda la Real familia» ${ }^{8}$. No nos debe sorprender el asombro del conde de Fuentes, pues, si bien el marqués de Ossun sospechaba tempranamente de la presencia de otros estamentos más ilustres entre el pueblo sublevado y él mismo comenzaba a oír el nombre de la Compañía como implicada, recomendaba al primer ministro francés prudencia en sus despachos con el embajador español: «Todo esto, señor, exige el máximo secreto, pues sin duda no ignoráis el señalado afecto que el conde de Fuentes ha profesado a la Sociedad de la que se trata»?.

4. Archivo General de Simancas (en adelante A.G.S.), Estado, leg. 4555, Magallón a Grimaldi, París, 17 de septiembre de 1764 .

5. Id, París, 21 de septiembre de 1764.

6. Id, París, 28 de septiembre de 1764.

7. La participación del conde en la Junta puede entenderse por el hecho de poseer información acerca del sangriento motín de Zaragoza. Por aquellas fechas regresó a su embajada. Isidoro Pinedo, en Manuel de Roda (su pensamiento regalista), Zaragoza, 1983, p. 94: «El conde de Fuentes no aportaba ninguna idea original y se conformaba en todo con las determinaciones que, como presidente del Consejo de Castilla, tomara su paisano el conde de Aranda». Fuentes se conformaba «con el pensamiento con que el conde. [de Aranda] desea reparar por medio de los buenos vasallos del Rey vecinos de Madrid representados en sus cuerpos, los excesos con que los malos y advenedizos que llenan este Pueblo el decoro y respeto de la Magestad»; en A.G.S., Gracia y Justicia, leg. 1009, Fuentes a Grimaldi, 8 de mayo de 1766.

8. A.G.S., Estado, leg. 4565, Fuentes a Grimaldi, París, 13 de mayo de 1767. Le comentó el conde una carta que Choiseul recibió de Ossun.

9. FERRER BENIMELI, J. A., «El motín de Esquilache y sus consecuencias según la correspondencia diplomática francesa. Primera fase de la expulsión y de la extinción de los jesuitas.», $A H S I$, año 53, fasc. 
Una muestra de este «afecto» que los coetáneos de Pignatelli vislumbraron se concretaba en la Carta de Hermandad que el conde había recibido de la Sociedad jesuítica como agradecimiento por su actuación, al conseguir que se devolviera a los ignacianos de la Provincia de Castilla una considerable cantidad de lanas que les había sido embargada en Francia en 1764, momento álgido del enfrentamiento en aquellas tierras contra los loyolitas ${ }^{10}$. El propio Fuentes era consciente de su delicada posición tras la expulsión de los regulares de España, con sus dos hermanos menores adscritos a ella: lo certifica el hecho de que tardara más de dos semanas ", desde el inicio del extrañamiento, en remitir a Grimaldi una carta en la que aludía al malestar que le producía la pertenencia de familiares tan próximos al Instituto. En ella relataba «el sentimiento grande, y vivo dolor que me ocasiona el tener dos hermanos en la Compañia, Provincia de Aragón [...]. Espero el favor de V.E. que poniendo mi rendimiento a los pies del Rey haga presente a S.M. mi aflicción, en la que no puedo hallar otro consuelo que considerar, que por ser aún mozos de 25 a 30 años (aunque ya sacerdotes) no aviendo podido tener ninguna parte en el gobierno de su Religión, estén tan distantes por esta circunstancia, como por sí mismos lo huvieran estado siempre, de poder incurrir personalmente en nada que fuese del Real desagrado de S. Magestad [...]. El Real Decreto les deja el consuelo de poder recurrir a la clemencia del Rey dejando la Religión: En ellos es menos difícil por no tener la última Profesión, y en mi indispensable la solicitud de que no queden individuos de un Cuerpo que el Rey ha extrañado de sus Dominios, y obedeciendo yo como debo la misma Real Resolución de no tener correspondencia con ellos, no encuentro otro medio de remitir a V.E. la adjunta Carta para nuestro Ministro en Roma, y las que escrivo a mis hermanos para que informando V.E. al Rey de su contenido, haga V.E. de ellas aquel uso que fuese del Real agrado de S.M. y decirme si será de su Real aprobación, que yo prosiga en escrivirles para continuar mis persuasiones, y informarme de su salud, remitiendo mis cartas, y ellos sus respuestas por mano de nuestro Ministro, o Agente en Roma $[\ldots]{ }^{\prime 2}$.

Es comprensible la retahíla de justificaciones esgrimidas por el conde de Fuentes en este su primer correo a Grimaldi relativo a la posición de sus hermanos donde, aparte del amor fraterno y la lógica preocupación por su suerte, es evidente el deseo del embajador de que esta situación no mancille su carrera. De ahí sus pasos comedidos a la hora de solicitar un canal de comunicación entre él y los padres José y Nicolás, resolviendo el Consejo Extraordinario, el 11 de mayo, responder después de la atenta lectura de la carta de Fuentes y permitir que «corran las dos Cartas que les Es-

105 (1984). Carta procedente de París, Archives Diplomatiques, Correspondence Politique, Espagne, 545, 208-211, El Escorial, 14 de julio de 1766, Ossun a Choiseul.

10. A.H.N., Estado, leg. 6544, Grimaldi a Fuentes, San Ildefonso, 20 de agosto de 1764.

11. El conde de Fuentes había recibido la comunicación de la decisión real el 2 de abril, y en carta del 8 de mayo comentaba las impresiones que este acontecimiento había causado en Francia; en A.H.N., Estado, leg. 3518, Fuentes a Grimaldi, París, 8 de mayo de 1767.

12. A.G.S., Estado, leg. 4565, Fuentes a Grimaldi, París, 17 de abril de 1767. 
cribe para que puedan solicitar la dimisoria, y proporcionar su regreso a estos Reynos, libres ya de la sugeción, dependiencia (sic), y conexión con la Compañía y su General», considerándose incluso conveniente esta medida «por que siempre la permanencia de sus dos hermanos en la Compañía daría una especie de apoyo, o esperanza, y confirmaría a muchos en la idea de quedarse» ${ }^{13}$.

La resolución del consejo Extraordinario se amplió a otros casos, empleando el recurso propuesto por Fuentes de 'que fuera el embajador en Roma, Tomás Azpuru, el intermediario de la correspondencia, y «convendría se le diesen instrucciones a dicho Ministro a efecto de que haga entender a los Regulares de la Compañía que por su conducto podrán manifestar las pretensiones y asuntos que les ocurran para que vistas por el Consejo Extraordinario a donde se remitan consulte a V.M. lo que se le ofreciese porque de esta manera reducida a una mano toda la correspondencia, las cosas irán con sistema y orden, y no habrá contradicciones en las providencias, y nadie tendrá motibo para tratar con los Jesuitas de otra manera» ${ }^{14}$.

Así, el marqués de Grimaldi pudo comunicarle al conde de Fuentes que «por el Extraordinario a Nápoles de mañana dirigiré a D. Tomás de Azpuru su carta y las otras dos» ${ }^{15}$, cosa que cumplió el secretario de Estado, aprovechando la ocasión para advertir al embajador en Roma que, aun habiendo sido prohibida la correspondencia de los vasallos con los regulares, «si algunos parientes de los expulsos de España, o estos mismos valiesen de su conducto para el solo fin de participarse recíprocamente su salud, pueda admitir las cartas abiertas, y que si tratasen de su dimisión de la Compañia y regreso a estos Reynos, lo avise V.E de oficio con informe individual de las calidades y circunstancias de los tales sugetos» ${ }^{16}$.

Estos planes iniciales se truncaron debido a la no admisión de los religiosos en los Estados que regía Clemente XIII. El clérigo zaragozano Tomás Azpuru, embajador de España en Roma desde los primeros meses del pontificado de Carlo Rezzonico, había conocido a principios de abril y de modo extraoficial, la actitud del papa ante el arribo de los jesuitas. En el breve Inter Acerbissimas, Clemente XIII lamentaba la determinación del soberano español y pedía el replanteamiento de las posturas. Pero, entre todos los desasosiegos que al Santo Padre produjo la actitud del Borbón, lo que más le molestó fue la unilateralidad de la decisión, esto es: la razón que explica la inconformidad papal del desembarco de los expulsos hay que buscarla en el pulso tirante entre el gobierno español y la curia romana, sintiendo la segunda la imposi-

13. A.G.S., Gracia y Justicia, leg. 667, Resolución del Consejo Exiraordinario, Madrid, 11 de mayo de 1767.

14. Ibídem. Se lee: Que los PP. Joseph y Nicolás Pignatelli habian debido embarcarse en el Puerto de Salou, con todos los demás individuos de la Provincia de Aragón, y que por consiguiente se halla, respecto a ellos executada la Real Pragmática quedando indefinidamente abierta la Puerta a qualquiera Jesuita para solicitar su dimisoria del General, y lograda pretender el regreso a estos Reynos vajo del Juramento y calidades que contiene para la debida precaución del Estado dicha Real Pragmática.

15. A.G.S., Estado, leg. 4565, Grimaldi a Fuentes, Aranjuez, 18 de mayo de 1767.

16. A.G.S., Estado, leg. 5044, Grimaldi a Azpuru, Aranjuez, 19 de mayo de 1767. 
ción de una potencia extranjera. El 2 de mayo de 1767 transmitió Jerónimo Grimaldi a Fuentes la noticia del previsible rechazo de los convoyes por parte de su Santidad, aunque «de todos modos arribarán allí los Jesuitas Españoles para que el Mundo y la Christiandad vean no omite el rey por su parte diligencia alguna», si bien «ha tenido el Rey por indispensable elegir otro parage donde se coloquen dichos regulares, para el caso de que la corte de Roma persista en su idea de no admitirlos: Y ha puesto la mira en la Isla de Córcega» ${ }^{17}$.

El embajador Pignatelli comentó acerca de la decisión papal que «encuentra este Ministro [Choiseul] muy extraordinaria la conducta de la Corte de Roma, aviendo admitido a los Portugueses; dice que no es fundada la recusación por la dependencia que tiene la Compañia mayor que ningún otro Orden religioso del Papa (como es verdad por su quarto voto) y cree el duque que si se huviesen desembarcado los Regulares en la Costa del Estado Pontificio, como con facilidad se pudiera aver ejecutado, estarían alli menos mal [...], y estando persuadido que una vez puestos en tierra, por la misma humanidad no podia el Papa dejar de proveer a su establecimiento» ${ }^{18}$. El conde de Fuentes transmitió al duque de Choiseul los deseos de Carlos III para que las tropas francesas existentes en Córcega acogieran con «humanidad» a los desterrados, comunicando, asimismo, a Grimaldi que al conocer el primer ministro francés que «tenía yo dos hermanos en la Compañia se diesen al Comandante de las tropas de Córcega las órdenes, que verá V.E relativas al alivio de estos infelices, lo que me ha sido de la mayor satisfacción por no aver mediado en esta resolución del Rey solicitud, ni la menor insinuación de mi parte» ${ }^{19}$.

El desvío de las flotas a Córcega motivó el escrito que Tomás Azpuru dirigió al conde de Fuentes: «de que por haverse variado el [destino] que trayan dhos PP. [Pignatelli] quando salieron de España, y pasado a la isla de Córcega, me parece, que la Real Orden se debe entender en las presentes circunstancias con el Ministro de S.M en la República de Génova, por cuya mano llegarán seguras a dhos PP. las Cartas de V.E y podrá tener con ambos la correspondencia, que S.M le permite» ${ }^{20}$.

Los hermanos del conde, tal como comunicó Azpuru a Grimaldi, ya se hallaban en Córcega, «pues venian en el Comboy del mando de Don Antonio Barceló, según he visto en la Lista, que me embió el Ministro Comisario del mismo, luego, que llegó al Puerto de Civitavieja he creído, deber dirigir dhas Cartas a Don Juan Cornejo Ministro de Génova»" ${ }^{21}$.

Juan Cornejo recibió las cartas, junto con la Instrucción del gobierno que le encargaba la recepción de las misivas que los parientes de los expulsos escribiesen. Cornejo se creyó en el deber de «hacer presente a V.E [Grimaldi] como abriéndose una tal Puerta de correspondencia, y comunicación a millares de cartas, que havia

17. A.G.S., Estado, leg. 4565, Fuentes a Grimaldi, París, 13 de mayo de 1767.

18. Id., Fuentes a Grimaldi, París, 13 de mayo de 1767.

19. Ibídem.

20. Id., Azpuru a Fuentes, Roma, 3 de junio de 1767.

21. Id., Azpuru a Grimaldi, Roma, 4 de junio de 1767. 
yo de leer atentamente, satisfaciendo a lo menos a las de los Principales sujetos de España, que con tal motivo escriviesen, me vería sacrificado a la más afanosa tarea, la qual ciertamente no sería possible desempeñasen mis ojos, y manos en el limitado tiempo, que de las 24 horas del día puede un hombre aplicar al trabajo, mediante la indispensable constitución de la humana débil naturaleza» ${ }^{22}$.

La carta del conde para sus hermanos llegó, después de tanto batallar, a manos de éstos. No se pudo hallar el manuscrito original del correo de Fuentes, como tampoco las respuestas que sus hermanos le remitieron, debido a ese peregrinaje de las misivas de un lado a otro ${ }^{23}$. De cualquier modo (por ejemplo, la Compañía había hecho pública en Roma, traducida al italiano, la respuesta que el padre José dio al conde), sí que se conoce el contenido de las mismas ${ }^{24}$.

Estas réplicas a la misiva de Fuentes fueron examinadas por el Consejo Extraordinario, y «ha visto el Consejo que son en respuesta a la que V.E les escrivió, persuadiéndoles como bueno y digno Hermano a que saliessen de la Compañia; y ha opinado con S.M. que mandó dirigirlas V.E para que vea la tenacidad con que los individuos de dho orden se han criado prefiriendo la suya a toda otra atención, y que S.M. manifieste a V.E. su agrado por el paso que dio con sus Hermanos de propio y pronto movimiento apenas supo la expulsión». Destacaba el Consejo que los hermanos de Fuentes «como sugetos de tanta distinción estarán ahora estrechamente acosados de sus principales compañeros lisongeándolos con ser las columnas de su apoyo y de su única esperanza, y que su misma bondad les havrá hecho susceptibles de la eficaz. impresión que manifiestan, y de haber dejado intervenir a los Padres gracias a la respuesta que dan a $V . E_{\gg}{ }^{25}$.

A pesar de la negativa de los hermanos de Fuentes a los intentos del embajador para que renegasen de su profesión, «esta resistencia suya no me hará mudar con ellos de lenguage, antes bien (pues S.M. ha tenido a bien permitirme escrivirles alguna vez) emplearé mi correspondencia en ver si puedo reducirlos a que salgan de la Orden, y a convencerse de que este es el partido que les conviene tomar, observando, como observaré siempre el mismo méthodo de hacer remitir mis cartas a Cornejo, encargándole recoja sus respuestas, y las remita a V.E. para que después de vistas se sirva darlas el curso que S.M. tuviese conveniente, y si se dignase aprobarlo, escrivi-

22. A.G.S., Estado, leg. 5651, Comejo a Grimaldi, Génova, 15 de junio de 1767.

23. MARCH, J. M, El restaurador de la Compañia de Jesús, Beato José Pignatelli y su tiempo, 2 vols., Barcelona, 1935, p. 216: «El P. Boero dice que encontró su traducción italiana en el Archivo General de la Compañia, del que fue archivero, y las publicó en su Vida del P. Pignatelli, de él las tomó el P. Nonell, traduciéndolas a su vez al castellano, sin advertencia alguna. Hoy ni siquiera aquella traducción italiana se conserva; al menos los que tienen cargo del Archivo no han dado con ella».

24. La carta de Fuentes a sus hermanos y la contestación de José se pueden encontrar en el libro del P. Luis Coloma, Retratos de antaño, XVI, Madrid, 1895, pp. 48-49; la contestación de Nicolás en el libro del P. March, p. 215. Fuentes les anunciaba su empeño en conseguir del Papa que pasaran a otra orden y del rey su regreso a España. Las respuestas, tanto de José como de Nicolás, rehusaban el ofrecimiento de su hermano mayor y persistían en su deseo de mantener su vocación, a pesar de los malos tiempos.

25. A.G.S., Estado, leg. 4565, Grimaldi a Fuentes, San Ildefonso, 3 de agosto de 1767. 
ré también a alguno de los comisarios nombrados los socorra de mi cuenta en las necesidades, que tuviesen ${ }^{26}$.

Córcega pertenecía a Génova desde 1274, pero desde esa fecha y hasta la llegada de los ignacianos, se había contabilizado también dentro de las posesiones de Alfonso V de Aragón en 1420, y de Enrique II de Valois en 1556. Francisco II, mediante el Tratado de Cateau-Cambrésis (1559), la devolvió a Génova, si bien continuó la resistencia corsa a la autoridad genovesa. En 1729 Génova quiso imponer en la isla diversos tributos, sirviendo este hecho como detonante de la sublevación de los corsos, quienes siempre habían mantenido vivo un espíritu independentista. El levantamiento triunfó y una asamblea general corsa proclamó en 1735 la segregación de Córcega de la órbita genovesa. La incapacidad de la República de Génova de imponer la paz con sus propios medios -y este es el factor que explica los sucesos posteriores--, obligó a solicitar la ayuda de Francia, derrotando a los rebeldes en diciembre de 1738 y permaneciendo las tropas galas en la isla hasta 1741, fecha en que la guerra contra Austria e Inglaterra compelió a Luis XV al acopio de todos sus efectivos. Desde entonces, Pasquale Paoli se convirtió en el caudillo de los insurgentes ganando terreno a Génova. Francia mandó tropas en 1752 para restablecer el orden, y también en 1756, ante un acercamiento de Paoli a Inglaterra que advertía de un posible desembarco de soldados ingleses en una isla tan apetecida por éstos como era Córcega. Por tanto, la ayuda de Francia a la República respondía a sus propios intereses, y ambos gobiernos consolidaron su relación con el Tratado de Compiegne de 6 de agosto de 1764, a través del cual Francia se obligaba a mantener guarnición durante cuatro años en las plazas costeras de Bastia, S. Florencio, Ajaccio, Calvi y Algaiola, siendo estas tres últimas, junto a $\mathrm{S}$. Bonifacio, las que recibirían a los jesuitas desterrados por Carlos III y repudiados por Clemente XIII ${ }^{27}$.

Consideraba el secretario de Estado que a la República de Génova le convenía la instalación de los jesuitas en sus plazas debido al beneficio que reportaría al comercio la circulación del dinero procedente de las pensiones de los expulsos (cien pesos anuales «a los de Misa» y noventa a los legos). Al estar estas plazas guarnecidas por tropas francesas, correspondía al embajador Fuentes obtener de la nación vecina las órdenes necesarias dirigidas a los comandantes de las mismas para consentir en ellas el acomodo de los religiosos. Así lo hizo Joaquín Pignatelli, obteniendo del duque de Choiseul la contestación de que «no avría dificultad en dar las órdenes, que yo [Fuentes] pedía; pero que en Córcega era tanta la escasez de Casas, y de viveres, que aún con el dinero faltaban a las Tropas; que preveía que los Jesuitas no podrían

26. Id, Fuentes a Grimaldi, Compiegne, 18 de agosto de 1767. El Consejo Extraordinario se conformó con la resolución del fiscal Campomanes y se le concedió a Fuentes el permiso para socorrer a sus hermanos en Córcega, vid. A.G.S., Gracia y Justicia, leg. 667, Consejo Extraordinario, 31 de agosto de 1767.

27. Sobre la historia de Córcega, MONTBAS , H. de., «Les jésuites espagnols et la réunion de la Corse a la France», Revue de Paris, 8 (1958), pp. 80-91; y sobre todo, VENTURI, F., Settecento Riformatore, «La rivolucione di Corsica», vol. V, parte $1^{2}$, Torino, 1987, pp. 3-220. 
dejar de perecer assí por esta razón, como por las circunstancias de aquel Pays, y los embarazos, que encontrarían a su arrivo, aún después de él» ${ }^{28}$.

En las conversaciones diplomáticas de Fuentes con Choiseul se obtuvo el consentimiento del desembarco, pero en la práctica este hecho sufrió una importante demora. El conde de Marbeuf, comandante general de las tropas acantonadas en la isla y responsable último de materializar el acuerdo alcanzado en París, escribió el 22 de mayo a su superior Choiseul exponiéndole la mísera situación del contingente militar en Córcega debido a la carestía de víveres y de viviendas ${ }^{29}$. Estos problemas que planteaba ya de por sí la isla, y que se agravarían en el caso del advenimiento de los regulares, motivaron la búsqueda de otra vía. Tal como informó el conde de Fuentes, el duque de Choiseul escribió a su representante en Génova, Boyer, «para que representando la imposibilidad de la subsistencia de los Jesuitas en Córcega pida a la República permita su desembarco en el Puerto de Génova, o en algún parage de la Ribera, según le pareciese, teniéndolos alli en depósito hasta tanto que informado el Rey N.S. disponga lo que se deberá ejecutar, pues de otro modo no puede la Francia dispensarse de embiar las segundas órdenes al Conde de Marbeuf (como lo executa) para que rehusando la Repca. el desembarco en el Continente, lo permita dicho Comandante en la Isla», aunque confiaba el primer ministro francés en la concesión de esta petición por parte de Génova y en que «podrán desde alli con más facilidad irse a la desfilada a los Estados del Papa» ${ }^{30}$.

Lo cierto es que mientras se mantenían estas negociaciones, la cruda realidad se iba imponiendo en los miembros de la expedición, para quienes todas las noticias, reuniones y decisiones diplomáticas tenían un carácter inesperado que los sumía en la confusión. Ya se habían sorprendido los integrantes de las naves comandadas por Antonio Barceló a su llegada a Civitavecchia el 11 de mayo, e igualmente se sorprendieron cuando arribaron pocos días más tarde (el 22) a tierra corsa y hallaron la negación del conde de Marbeuf a su desembarco, quien relató a su superior «que casi al mismo tiempo que avía recivido las órdenes de esta Corte [francesa] para recibir a los Jesuitas Españoles, avian llegado dos Embarcaciones de éstos escoltadas de algunos xabeques, y que consecuentemente a lo que tenía representado las avía hecho ver la imposibilidad de poderse alojar y subsistir en la Bastia, lo primero por no aver en ella más que 200 Casas, y estar la mayor parte de éstas ocupadas con las Tropas Francesas de su mando, y lo segundo por no aver víveres para poderse mantener; que después de esto les avía persuadido tomasen el partido de ir a Génova, en donde tal vez los recivirian» ${ }^{3 i}$.

En la corte de Madrid empezaba a dudarse de las órdenes que, según narraba Fuentes, Choiseul despachaba a Marbeuf: retraso, confusión y, recurriendo a un cali-

28. A.G.S., Estado, leg. 4565, Fuentes a Grimaldi, París, 13 de mayo de 1767.

29. Ibidem, Bastia, 22 de mayo de 1767, Marbeuf a Choiseul.

30. Ibidem, Marli, 31 de mayo de 1767, Fuentes a Grimaldi.

31. Ibidem, París, $1^{\circ}$ de junio de 1767 , Fuentes a Grimaldi. 
ficativo suave que no enturbiase las relaciones de las dos familias borbónicas, «inconsecuencia» ${ }^{32}$. Inconsecuentes lo eran para los planes de Carlos III, pero no para los objetivos del gobierno galo que no eran otros que conseguir «de la incómoda posición de España informaciones de interés [derivadas de la pesquisa secreta] y compromisos de futuro [contar con el apoyo español en una futura anexión de la isla] ${ }^{33}$.

La previsión de Choiseul de que la República de Génova admitiría en el continente a los ignacianos fue errónea: se negó ésta «absolutamente a recivirlos, no dando otra causal (sic), sino la de la quietud, y seguridad pública», con lo que el duque volvió a escribir a Marbeuf -siempre según el relato de Fuentes, que no guardaba sospecha del ministro francés- «para que reciva a los Jesuitas de cualquier modo que sea en las Plazas de su mando, y previniéndole al mismo tiempo, que como es imposible que ellos, y las Tropas puedan subsistir, según el mismo Marbeuf tiene representado, haga embarcar, y salir de dichas Plazas tres Batallones de los siete, que hay en ellas, pidiendo al Comandante de nuestras Embarcaciones que los reciva a bordo para traherlos a Francia» ${ }^{34}$.

Evidentemente, la solución que proponía Choiseul era del todo ilógica y, siguiendo las pautas anteriores, inconsecuente. Tanto para la corte de Madrid como para la de Génova el abandono de las tropas supondría la ocasión idónea para que P. Paoli asestara el golpe definitivo a la soberanía genovesa y se hiciera con el control insular, teniendo entonces Inglaterra un buen puerto de apoyo en sus relaciones comerciales y un bastión ofensivo-defensivo en tiempos de guerra. Con una ingenuidad impropia de un político como Choiseul, expidió el duque un correo a Marbeuf «con el fin de escribir a Paoli, expresándole, que espera que sin embargo la salida de dichas Tropas, respetarán los Corsos las Plazas de la misma manera que si no hubiesen salido, y que estuviesen aún guarnecidas por las Tropas del Rey» ${ }^{35}$. El conde de Fuentes se encargó de transmitir la poca fiabilidad de dicha maniobra, aconsejando al mandatario francés el mantenimiento de, al menos, un piquete en cada una de las tres Plazas - Calvi, Ajaccio y Algaiola- previstas a evacuar; respondió Choiseul que los corsos, al verlas tan débilmente protegidas, quizás las atacasen y el resultado «sería indecoroso para la Francia ${ }^{36}$. Pero el plan del primer ministro de Luis XV no era tan temerario como a simple vista pudiera parecer, pues, a pesar de desguarnecer los tres presidios mencionados, Bastia y $\mathrm{S}$. Florencio seguirían manteniendo los dos batallones que cada una acogía, siendo estos dos enclaves los más estratégicos y decisivos para la conservación de toda la isla y quedando ambos preservados de la admisión de los religiosos. Precisamente en la rada de S. Florencio permanecían anclados los bu-

32. A.H.N., Estado, leg. 3518, Grimaldi a Fuentes, Aranjuez, 19 de junio de 1767.

33. GIMÉNEZ LÓPEZ, E., «El ejército y la marina en la expulsión de los jesuitas de España», Hispania Sacra, XLV (1993), pp. 577-629, en concreto p. 618.

34. A.G.S., Estado, leg. 5044, Fuentes a Grimaldi, París, 19 de junio de 1767.

35. A.G.S., Estado, leg. 4565, Fuentes a Grimaldi, Compiegne, 23 de julio de 1767.

36. Ibidem, Compiegne, 27 de julio de 1767, Fuentes a Grimaldi. 
ques integrantes de las expediciones comandadas por Vera, Lombardón y Argote, mientras que en Bastia eran las naves de A. Barceló las que aguardaban la indicación de un destino.

Cuando los diplomáticos dilucidaban en París lo contraproducente o no de la evacuación de las plazas, Marbeuf recibía las órdenes de Choiseul y transmitía el 2 de julio a los jesuitas la decisión del duque, que no era otra que proceder a su acomodo en los presidios establecidos, con lo que las naves iniciaron nuevamente la travesía hacia los puntos de atraque asignados a cada provincia. El 14 de julio desembarcaron los padres andaluces en Algaiola ${ }^{37}$, y los castellanos en Calvi. Los miembros de la provincia de Toledo y Aragón se toparon con las dificultades que detallamos a continuación.

A Francisco de Vera y Antonio Barceló se les había señalado la plaza de Ajaccio como destino último del largo periplo iniciado en la costa española, y hacia allí dirigieron sus respectivos convoyes. La evidencia de un ataque corso ocasionado por el traslado de los franceses y la pervivencia de los genoveses, determinó en el ánimo de ambos comandantes lo inapropiado del abandono de los ignacianos en tales circunstancias. El 9 de agosto escribió Juan Cornejo, cónsul español en Génova, aprobando la decisión de los marinos y ordenando poner rumbo al puerto de Bonifacio, en donde con anterioridad había contactado Vera con el «Comisario Vize Gerente de Bonifacio, preguntándole el número de Padres que podrían alojarse allí, y me respondió con fecha de 15 deste [agosto], que 400 con cuya noticia positiva resolví (y lo mismo D. Antonio Barceló) pasar a dicho puerto con ambos Combois» ${ }^{38}$. Pero los capitanes subordinados a Vera se negaron a realizar esta travesía por cuanto el puerto de Bonifacio, estrecho y de bajo fondo, no ofrecía garantías para el éxito de la operación. Las naves de A. Barceló, mejor preparadas, sí enfilaron hacia allí y, merced a que el número de viajeros del convoy de Aragón superaba ya los cuatrocientos, decidió Francisco de Vera ponerse en derechura a Génova, en cuyo puerto esperó nuevas instrucciones. Éstas exigieron al comandante Vera su regreso a la isla y el hospedaje de los padres toledanos en su primitivo destino, Ajaccio ( 23 de septiembre), a pesar de la situación y del ofrecimiento de Choiseul de alojo en Bastia haciendo acampar en los alrededores las tropas de la guarnición ${ }^{39}$. Esta oferta del duque no iba a ser desairada, pues ya desde Madrid se pensaba en Bastia como lugar de acomodo de «cerca de dos cientos [jesuitas] que están promptos a embarcarse en Cartagena», la mayor parte de ellos ignacianos que llegaban de América y varios procuradores que se habían queda-

37. GIMÉNEZ LÓPEZ, E. y MARTÍNEZ GOMIS, M., «Los diarios del exilio de los jesuitas de la provincia de Andalucía (1767)», Revista $H^{\alpha}$ Moderna, Alicante, ${ }^{\circ}$ 13-14 (1995), pp. 211-252. Del Diario de Navegación del P. Alonso Pérez se lee: «Bahía de Algayola, entre ella y Calvi, 14 de julio, a las 7 de la tarde, ya dado fondo en ella sabemos que toda Ia provincia de Andalucía esta noche desembarcamos, y nos alojamos en Algayola para vivir en ella. Dios nos asista en esta infeliz tierra.», p. 241.

38. A.G.S., Estado, leg, $4565, F$. de Vera a Juan Cornejo, a $2^{1 / 2}$ leguas de distancia del pto. de Génova, 28 de agosto de 1767.

39. Ibidem, París, 11 de septiembre de 1767, Fuentes a Grimaldi. 
do en la Península para ayudar a los oficiales reales en la investigación de las casas jesuíticas ${ }^{40}$.

Al igual que estos procuradores jesuitas colaboraron en España, el Consejo Extraordinario había decidido ya en junio el nombramiento de dos comisarios, Gerónimo Gnecco y su hijo Luis, para apoyar a los expulsos, sobre todo a la hora de suministrar víveres y entregar las pensiones con las que amortizar el abastecimiento ${ }^{41}$. No hay que olvidar que una de las razones blandidas al gobierno genovés para convencerle de la conveniencia de la admisión de los expulsos en Córcega era la circulación de los varios miles de pesos procedentes de las pensiones concedidas por Carlos III. Gerónimo Gnecco se encargó del aprovisionamiento en Génova y su hijo, en Bastia, recibía los géneros e iniciaba su distribución al resto de los presidios. Los jesuitas, en cambio, preferían buscar otra fuente de suministro y dudaban de la honestidad de los Gnecco, cuyas competencias empezaron a rebajarse tras la designación en julio de dos comisarios reales ${ }^{42}$, Pedro Laforcada, oidor honorario de la Chancillería de Granada, y Fernando Coronel, comisario de Guerra. Se solicitó al embajador Fuentes que ambos fueran reconocidos por las autoridades francesas en Córcega, donde debían «revistar los Jesuitas expulsos de España, celar su conducta, y tomarles Declaraciones en punto de haciendas, y efectos que han poseído» ${ }^{43}$. Llegaron a la isla a principios de noviembre, mes en el que un nuevo golpe se asestaba contra la Compañía al confirmarse su expulsión de Nápoles.

La noche del 20 al 21 de noviembre de 1767 empezó en la ciudad de Nápoles el arresto de los religiosos, proceder que en los días sucesivos iban a imitar el resto de núcleos poblacionales que acogían jesuitas, con lo que abandonaban éstos los enclaves regidos por el Borbón y se dirigían, unos por tierra y otros por mar, a suelo pontificio.

Clemente XIII tuvo que aceptar resignado esta nueva muestra de irreverencia -según la curia romana- que suponía la introducción forzosa en sus Estados del contingente de religiosos. La opinión, en cambio, del duque de Choiseul -compartida por el resto de gobernantes «laicos»- exponía que «lo que el Gobierno de Nápoles avía hecho avía sido lo que suele, y puede hacer cualquier Príncipe, esto es poner al que destierra a la frontera del propio Estado, y intimarle que salga de él: que la situación del Reyno de Nápoles hacía indispensable lo que avía sucedido, y que por la misma razón el Papa era Dueño de volver a hacer salir a los Jesuitas, o a otros qualesquiera de sus Estados por la misma regla» ${ }^{44}$, aunque el Pontífice, a la vista de la

40. Ibídem, 28 de septiembre de 1767, Grimaldi a Fuentes.

41. GIMÉNEZ LÓPEZ, E. y MARTÍNEZ GOMIS, M., «Un aspecto logístico de la expulsión de los jesuitas españoles: la labor de los comisarios Gerónimo y Luis Gnecco (1767-1768)», Actas de la III Reunión Cientifica de la Asociación Española de Historia Moderna, Las Palmas de Gran Canaria, 1994, pp. 303-314.

42. A.H.N., Estado, leg. 6554, Grimaldi a Fuentes, Madrid, 13 de julio de 1767.

43. A.G.S., Estado, leg. 4565, Fuentes a Grimaldi, Compiegne, 27 de julio de 1767.

44. A.G.S., Estado, leg. 4565, Fuentes a Grimaldi, París, 25 de diciembre de 1767. 
delicada posición de los ignacianos establecidos en Córcega, acató «humanitariamente» el hecho consumado de la presencia de los procedentes de las Dos Sicilias.

Mientras la operación en el reino napolitano se ponía en práctica, un flamante dilema -previsible, por otro lado- surgió con la necesidad de alojar a los jesuitas de las siete provincias de ultramar ${ }^{45}$, que se distribuían en las ciento treinta y una casas regentadas por los padres y que, en un número aproximado de dos mil, se vieron, al igual que sus hermanos peninsulares, obligados al destierro.

El prendimiento de los hispanoamericanos empezó a certificarse en el mes de julio y se desarrolló de forma encadenada mediante los preceptos que escalonadamente propalaban los respectivos gobernantes de las demarcaciones a evacuar, encontrándose en enero de 1768 en la Península Ibérica prestos a embarcar la mayoría de los desterrados, si bien el proceso en las Indias se prolongó más tiempo a causa de la mayor extensión geográfica -que favoreció la dispersión de los jesuitas- y la inferior disponibilidad de recursos. El marqués de Grimaldi no deseaba que en el fondeo de este nuevo grupo a Córcega se produjeran los mismos escarceos que con los peninsulares que les habían precedido, y encomendó al conde de Fuentes que se dispusiesen las medidas precisas para recibirlos en el presidio de Bastia e, incluso, en el interior de la isla donde Paoli imponía su ley; más aún, la postura de Grimaldi de que no se ofuscase el proceso y quedara en mal lugar la intendencia española, ambicionaba un objetivo más: disponer facilidades para que cuantos ignacianos anhelasen abandonar Córcega lo hicieran, siempre y cuando no se dirigieran a ninguna de las haciendas reales. El embajador Fuentes le escribió a finales de noviembre de 1767 contestando a su petición acerca de «las órdenes, que este Ministerio [Choiseul] ha de dar al conde de Marbeuf, para que procure ir estableciendo en Córcega los Jesuitas, que se le fueren embiando de España, que se introduzcan en lo interior del Pays, mediante la condescendencia de Paoli, quantos más Regulares sea posible, y que apadrine directa, o indirectamente aquellos que quisiesen irse fuera de la Isla $\rangle^{46}$.

Si Francia expuso ante la llegada de los religiosos españoles las ya mencionadas protestas relativas a la dificultad de su alojamiento y manutención en un territorio en el que las guarniciones galas sufrían esas contrariedades, es lógico inferir que la pauta de la nación vecina persistiese frente la aparición de los jesuitas americanos. Choiseul escribía a Pierre Paul d'Ossun, embajador en España, refiriéndose al trance para «l'emplacement de'ce grand nombre de Jèsuites» que «mourant de faim et de misere, et désertant lorsqúilre en trouvent l'occasion ${ }^{47}$. Pero esta inicial actitud clarificadora de las penalidades que arreciarían con la comparecencia de un número, todavía indeterminado, de ignacianos en la isla mediterránea, se tornó recelosamente condescendiente con el laudo de la corte madrileña. ¿Qué puede explicar el lance de que el conde de Marbeuf suavizara los requisitos para la admisión de una buena cantidad de expulsos en Bastia, donde se acantonaba su cuartel general?

45. Nueva España, Quito, Nuevo Reino de Granada, Perú, Chile, Paraguay y Filipinas.

46. A.G.S., Estado, leg. 4565, Fuentes a Grimaldi, 20 de noviembre de 1767.

47. Ibidem, Fontainebleau, 12 de octubre de 1767. Copia de la carta de Choiseul a Ossun. 
Para el logro del acomodo de los jesuitas de ultramar en Bastia, la diplomacia española trabajó desde París -Fuentes con Choiseul-y desde Córcega, donde el comisario Gerónimo Gnecco se responsabilizó de explicar personalmente a Marbeuf los planes del gobierno carolino, que no eran otros que habilitar en el mencionado enclave viviendas que arrendar a los americanos. Desde Génova, el mayor de los Gnecco debía gestionar el abastecimiento de los religiosos -víveres repelidos por éstos, lo que demuestra que las carencias de la isla, salvo en puntuales momentos, no debieron ser tan agobiantes-, y su hijo Luis quedaría en Bastia ocupado en los preparativos. No obstante, este propósito primitivo fue hábilmente explotado por Francia, país que, según el Tratado de Compiegne, debía abandonar Córcega en 1768, acontecimiento que no convenía ni a la República de Génova -sin medios para garantizar la armonía y su soberanía - ni a la misma nación gala, que con probabilidad vería asentarse en un territorio tan próximo a ella tropas inglesas dispuestas a ejercer desde la isla mediterránea una estratégica vigilancia y control. Así que la afirmación positiva de Marbeuf a la elección de Bastia como lugar de recogida de los desterrados obedecía a la intención de emplear toda la infraestructura y víveres que España iba a costear y que esperaba amortizar mediante las pensiones de los propios jesuitas.

Llegaron los padres de ultramar a Ajaccio (costa occidental) el 8 de julio de 1768, y entraron en Bastia el 7 de agosto. En aquellos momentos ya se estaba configurando la idea de que los ignacianos se encarrilasen hacia su «natural destino» a través de una fórmula que la Santa Sede no sintiera como impuesta por parte de una autoridad foránea. La conducta elegida fue procurar que Génova admitiese en sus costas el desembarco del grupo jesuítico y, a partir de ahí, distribuir las diferentes provincias en los Estados papales. Los primeros en mudar de residencia, el 30 de agosto, fueron los recién llegados. El 18 de septiembre se ausentaron de Córcega los peninsulares, apareciendo en Sestri (parte oriental de Génova) un mes más tarde e instalándose a finales de octubre y principios de noviembre a lo largo de las urbes vinculadas a la esfera vaticana ${ }^{48}$, en un desarrollo que tampoco se vio libre de fatigas: «Por nuestro $\mathrm{Mi}$ nistro de Génova -refería Fuentes a Grimaldi- don Juan Cornejo habrá sabido V.E el embarazo en que se hallaba la República, él mismo, y aún el Ministro de Francia Monsieur Boyer sobre el recibo y avio de los Jesuitas de Córcega que debían salir todos de la Isla en virtud de las órdenes de Monsieur de Chauvelin [el nuevo jefe militar de la isla] y atravesar por una parte de los estados de Génova, por los de Parma y Módena para venir a parar en los del Papa». El duque de Choiseul aconsejó «conducir los Jesuitas en derechura a los Estados del Papa, y desembarcarlos en ellos, si subsisten siempre las dificultades de no poder disponer que vayan por tierra, como

48. En Bolonia y su campiña, los de Castilla alternando con los hispanoamericanos y filipinos; en Ferrara los de Aragón; en Rímini los andaluces y en Forli los de la provincia de Toledo. Su asentamiento en Italia: GIMÉNEZ LÓPEZ, E., y MARTÍNEZ GOMIS, M., «La llegada de los jesuitas expulsos a Italia según los Diarios de los padres Luengo y Peramás», en Expulsión y exilio de los jesuitas españoles, GIMÉNEZ LÓPEZ, E. (editor), Universidad de Alicante, 1997, pp. 197-213. 
se había proyectado y empezado a practicar» ${ }^{49}$. Este «embarazo» aludía a clarificar a quién competía cargar con los gastos que conllevaba el traslado por tierra. El marqués de Grimaldi remitió a Fuentes la decisión de Carlos III acerca de este asunto, quien dictaminó «que se consideren de extraordinario, además de una primera asignación, quarenta pesos a cada Jesuita de los que llevan intención de secularizarse en Roma, $y$ veinte a los que emprendan el viage perteneciendo en el gremio de la Compañia, cuia diferencia lleba el fin de promover la secularización» ${ }^{50}$.

La expiración en 1768 del Tratado de Compiegne dejaba a Génova en una problemática tesitura para mantener su bandera frente al ímpetu corso; ello constriñó a la República a decidir el futuro del emplazamiento mediterráneo: un nuevo tratado signado el 15 de mayo de 1768 estipulaba su cesión a Francia por dos millones de francos. Y una cosa era para la nación gala colaborar con Génova contra los descontentos comandados por Paoli, y otra muy distinta hacerse con la titularidad jurídica de la isla, convertida en dominio de Luis XV y donde, por tanto, sería ilógica la supervivencia en ella de los regulares.

La postura del duque de Choiseul en el momento en que se acercaba el año de $1768 \mathrm{y}$, por tanto, la salida de las tropas francesas de la agreste tierra corsa, era de no prorrogar su estancia allí. Sorba, enterado del pensamiento del ministerio francés, y conocedor igualmente de las buenas relaciones que unían a Choiseul con Fuentes, recurrió al embajador hispano «para que yo me interese en su pretensión» ${ }^{51}$, que no era otra que conseguir del rey cristianísimo la permanencia de su ejército por más tiempo. El interés de España por la conservación de cierta autoridad en la isla no era baladí, pero desde Madrid se recomendaba al embajador ir con tacto y sutileza para que no se asemejase a una intromisión en cuestiones que competían a Francia y a Génova. Narró el marqués de Grimaldi a Fuentes que «siendo indubitable que nos traería malas consecuencias [...] el que sacudiendo los Corsos la obediencia de la República permitiessen algún Establecimiento en ella a los Ingleses para apoyo de su libertad, parece no sea negocio aquél que esta Corte deba entregar a la indiferencia; pero como de entrar V.E a tratarlo de oficio podría resultar que se le digesse que tomássemos parte en él pues también nos interesa respecto al systhema de unión, no cree S.M conveniente que lo egecute V.E como nacido de su orden, sino que hable V.E a Choiseul tomando motivo de aver solicitado Sorba su recomendación, y que le haga las reflexiones que hai para que essa Corte no abandone a la suerte la de la Isla de Córcega» ${ }^{52}$. El conde de Fuentes se anticipó a esta providencia, ya que antes de tener constancia de las palabras precedentes tuvo ocasión de hablar con el duque de esta materia, «y sin darle a entender, que me le hubiesse tocado Monsieur de Sorba le hice ver, que de abandonar la Isla de Córcega podían resultar en todos tiempos conse-

49. A.G.S., Estudo, leg. 4565, Fuentes a Grimaldi, París, 19 de septiembre de 1767.

50. Ibídem, S. Ildefonso, 19 de septiembre de 1767, Grimaldi a Fuentes.

51. Ibidem, París, 15 de marzo de 1767, Fuentes a Grimaldi.

52. Ibídem, El Pardo, 25 de marzo de 1767, Grimaldi a Fuentes. 
quencias mui contrarias al sistema de unión de nuestras dos Cortes, en cuyo plan debian entrar como objetos principales el reducir a la Inglaterra, sacándola del Mediterráneo algún día, la extensión de nuestras costas y la de los Reynos de Sicilia, vistas que jamás pueden realizarse, sino se procura proporcionar los medios con mucha anticipación, y quitar los embarazos que pueden impedir el efecto, y que sin duda lo sería si abandonada la Córcega a su suerte se hiciessen dueños de algún puerto los Ingleses, porque los malcontentos los hubiessen llamado, o por que los mismos Ingleses quisiesen apropiarse la Isla, y substraerla de la soberanía de la República» ${ }^{53}$. Fernando Coronel, uno de los comisarios españoles en Córcega, advertía al conde de Aranda «informándole de las sospechas que tiene de que los Ingleses puedan pensar en apoderarse del puerto de Ajaccio en Córcega» ${ }^{54}$.

No sólo los ingleses representaban una amenaza: a España también le preocupaba el cobijo que los berberiscos podían obtener en una Córcega desprotegida . «El objeto que directamente nos interesa, así como a las dos Sicilias y otras Potencias de Italia, es que se asegure bien en el tratado de cesión el que aunque la Francia tenga paz con los Berberiscos, haya de exceptuarse en ella la Córcega, porque si en esta Isla hallasen entrada y abrigo, se doblaría el perjuicio que causan a nuestra navegación y comercio» ${ }^{55}$, encomendándosele a Fuentes velar por este punto. Y parece ser que la gestión del conde tuvo efecto en las disposiciones del tratado, ya que se accedía a la demanda española ${ }^{56}$.

Nuestro embajador no dudaba el 30 de abril de 1768 que el acuerdo para la cesión estaba prácticamente establecido, pero de nuevo se renovaba el interrogante de qué hacer con los jesuitas, sujetos pasivos en todo este proceso y, al mismo tiempo, protagonistas de las consecuencias de esta negociación. Choiseul declaró a Fuentes el envío a la isla de doce o catorce batallones y de dos legiones, tropas que, junto con los soldados ya existentes en Córcega, serían comandadas por el marqués de Chauvelin: «Con esta ocasión me ha añadido, que esta novedad hacia imposible la subsistencia de los Jesuitas en aquella Isla, no solamente por lo respectivo a los Viveres, y habitación, sino también por otros embarazos e inconvenientes que podrian resultar de estar en los mismos parages que la tropa: que por esto había pensado (teniendo antes el beneplácito del Rey) el embarcarlos todos, y llevarlos a Civitavecchia y Es-

53. Ibídem, París, 13 de mayo de 1767, Fuentes a Grimaldi.

54. Ibidem, París, 18 de abril de 1768, Fuentes a Grimaldi. El 6 de junio escribió Fuentes desde París que «no se persuade el Duque que el Ministerio Inglés anticipe por esto [el Tratado de 1768] un rompimiento en la situación en que se halla, pero cree que puede suceder embíe bajo mano socorros a Paoli, en cuyo caso podría acontecer mui bien que la imprudencia de un Capitán de fragata Inglés empeñase a la Francia, y por consiguiente a nosotros en una Guerra.»

55. Ibidem, El Pardo, 14 de marzo 1768, Grimaldi a Fuentes.

56. Ibídem; el artículo 8 del Projet de Convention entre le Roy et la Republique de Genes estipulaba la no admisión de los berberiscos «dans les ports, Rades, et Plages occupés par las Troupes du Roy en Corse.» Así aprobaba el rey Católico la cesión de Córcega a Francia, en A.H.N., Estado, leg. 6558, Grimaldi a Fuentes, Aranjuez, 16 de mayo de 1768. 
tados del Papa: que ya no estamos en tiempo de tener contemplación alguna por Roma; y que a más de esto las cosas havían mudado de manera, y particularmente el systema de aquella Isla, que el partido de sacar a los Jesuitas de ella, y llevarlos a los Estados del Papa era un efecto absoluto de la necesidad». Proseguía Juan Joaquín Pignatelli esbozando su opinión respecto al juicio del mandatario galo, pudiendo intuir los lectores actuales un factor más de los que él mismo resalta para dar su conformidad a los criterios de Choiseul: lo que supondría este hecho en la mejora de las condiciones de vida de sus hermanos. Discreto en su ánimo personal, leemos: «A mí me parece que este pensamiento del Duque no sólo es conforme a lo que desde el principio se deseó, esto es, de desembarcarlos en aquellos Estados, sino que haciéndolo por sí la Francia, no es ya la acción del Rey, y por consiguiente no puede haber queja ninguna fundada contra nosotros de la parte de Roma; fuera de que la conducta que esta Corte ha tenido y tiene nos dispensa enteramente de observar aquel miramiento y consideración que se quiso tener al principio» ${ }^{57}$. Grimaldi corroboraba las apreciaciones de Fuentes: «Sobre todo soverano de la Córcega el Rey Christianísimo es dueño de hechar a los Jesuitas, ¿y adónde se han de llebar si no a Roma?». De todas formas, el embajador debía matizar el contento del gobierno español, ya que «si el Duque notasse lo fáciles que somos ahora en condescender al envío de los Jesuitas a Roma, y lo cotejasse en nuestro Empeño de fijarles en Córcega, para que no crea nace de que ahora son ellos los que dan este golpe a Roma expóngale V.E que para nosotros son mui diferentes las circunstancias. Entonces recién hechados los Jesuitas no queriamos aumentar la fermentación que podrían causar sus apasionados bajo el pretexto de que insultábamos al Papa, y a todo lo sagrado. Ahora está aterrada la fermentación y más abiertos los ojos de la nación» ${ }^{58}$. Palabras que reflejan una vez más el comedimiento y precaución con que debía andar el conde de Fuentes en el espinoso tema de los jesuitas, a pesar de la «consanguineidad» y de la afabilidad en el trato de ambas coronas.

Fue don Felipe de Borbón, hermano de Carlos III, quien inició -bajo la dirección del ministro Guillaume du Tillot- una serie de medidas tendentes a configurar una estructura política, económica y social más acorde con la tónica reformista del momento y en la que no tenían cabida las reminiscencias feudales todavía presentes en Parma, un ducado repleto de inmunidades y privilegios eclesiásticos. Francia y España apoyaron la política del duque y, al relacionarse el pequeño enclave italiano en los problemas de mayor envergadura que mantenían Luis XV y Carlos III con el Sumo Pontífice, el ducado se convirtió en el flanco más débil de la dinastía borbónica y, por consiguiente, el más vulnerable a la hora de descargar la cólera reprimida ${ }^{59}$. La amonestación Alias ad apostolatus, del 30 de enero de 1768, supuso la condena al gobierno ducal, reclamando el retorno a la soberanía de esos dominios al papado.

57. Ibidem, París, 30 de abril de 1768, Fuentes a Grinaldi.

58. Ibidem, Aranjuez, 16 de mayo de 1768, Grimaldi a Fuentes.

59. VENTURI, F., op. Cit., vol.II., p. 227. 
Parma, lejos de amilanarse, resolvió el 3 de febrero la expulsión de los jesuitas (unos 170). El 19 de febrero recompuso Fuentes a Grimaldi el diálogo establecido con Choiseul acerca de los sucesos de Parma, considerándolos el ministro francés «un golpe de despique» y esbozando la necesidad de una satisfacción, porque si no se llevaba a cabo sería «bolver a los antiguos tiempos de la ignorancia, y a Roma su pretendida authoridad, y antiguas armas, con que avía dominado a las Naciones, por tantos siglos, quitando a los Reyes la propia natural jurisdicción, que constituye la regalia, y el esplendor de la Soberanía ${ }^{60}$. Sorprende como en fecha tan temprana ya hablaron el duque de Choiseul y el embajador español de las medidas que a los pocos meses se materializarían: Francia ocuparía Aviñón y a España, a juicio del conde, le convendría «que S.M mandase correr la Pragmática [del «exequatur»], que tuvo por conveniente hacer, y que después se mandó suspender» ${ }^{\circ 1}$. O no sorprende tanto si conocemos el substrato regalista que crepitaba en la política y que sólo precisaba de puntuales detonantes -como el Monitorio- para aflorar en toda su magnitud.

Choiseul había mostrado el parecer de remitir un memorial conjunto de las tres monarquías borbónicas al papa expresando su disgusto. Clemente XIII rechazó la primera instancia que el embajador español destacado en Roma, don Tomás Azpuru, cumplió para que el pontífice reconsiderase su conducta. Ante tal determinación, el tiempo de poner en práctica el castigo previsto (la ocupación de Aviñón por parte de Francia y de Benevento y adyacentes por parte de Nápoles) se acercaba, y el trabajo del conde de Fuentes para coordinar la ejecución de las mismas junto con Francia y Nápoles fue cultivado con eficacia. Clemente XIII tuvo noticia el 14 y el 19 de junio, respectivamente, de la anexión de Benevento y Pontecorvo más la de Aviñón ${ }^{62}$.

La casa de Borbón, a las dos proposiciones tenidas por ineludibles - la consabida revocación del Monitorio contra Parma y el reconocimiento de la soberanía del duque- para restablecer una comunicación fructífera con la Santa Sede, creyó «mui acertado encajarla la tercera, separadamente que es la de extinguir la Compañia. Aunque por descontado no se logre el efecto, será siempre útil el aver soltado la Piedra, para que el General de la Orden, y sus Secuaces, se desengañen de la reconciliación con las Potencias de Borbón». Es decir, el llamado Monitorio de Parma ofrece un contexto en el que apoyar un pensamiento originado tiempo atrás, siendo conscientes que, aunque «no se logre el efecto» y se concibiera «separadamente» del negocio de Parma, serviría en la preparación de un camino que, sin lugar a dudas y sin visos de «reconciliación», iba a recorrerse en dirección a la extinción de la Religión jesuítica. Faltaba oír la voz de Nápoles y Francia, atañendo al conde de Fuentes «soli-

60. A.G.S, Estado, leg. 4565, Fuentes a Grimaldi, París, 19 de febrero de 1768.

61. Ibidem.

62. A.H.N., Estado, leg. 5560, Azpuru a Fuentes, Roma, 29 de junio de 1768. Narró monseñor Azpuru al embajador Pignatelli que, tras la ocupación de Benevento, Pontecorvo y Aviñón, «los jesuitas están llenos de miedo, recelando que entren las tropas en Roma y asalten sus colegios». 
citar que allí [París] se adopte esta idea, que aquí todos miran por oportuna y conveniente» ${ }^{63}$.

El conde de Fuentes, en carta escrita el 8 de mayo de 1767 a Grimaldi, demostraba su empatía con Choiseul en el negocio de la extinción, al considerar «que me parecía que el Papa debiera reformar del todo la Religión [jesuítica], pues además que no teniendo territorio en la Christiandad, donde pueda subsistir, ni ejercitar sus Misiones, pues sólo son nuestros Dominios, los de Francia, y de Portugal los que confinan con los Infieles donde se empleaban, creía yo que prescindiendo de esta imposibilidad, avía poderosíssimas razones, para que la Corte de Roma se prestase a la extinción de esta Religión, pues además de hacer infelices inútilmente a los inocentes, que hoy están ligados a ella [pensaba, sin duda, en sus hermanos, lo que justifica sus prontos requerimientos a la abolición], sería extinguir también los partidos, $y$ controversias, que animados de la tolerancia podían ser de funestísimas consecuencias a la misma Iglesia, y Estados; me respondió el Duque, que assí lo comprendía también, y que esto mismo lo avía escrito a su Embajador el Marqués de Aubeterre para que se lo dijese al Papa» ${ }^{64}$. En efecto, Aubeterre mantuvo una audiencia con Clemente XIII en la que reveló a Su Santidad la reflexión de Choiseul, dando Francia el primer paso frente a la Santa Sede en el programa extintor.

Sin embargo, de esta iniciativa francesa no deducía Fuentes ulteriores muestras, por parte de Versalles, a encabezar -o siquiera participar activamente- la negociación: veía a Luis XV indeciso por creer el soberano que deberían proceder de España las explicaciones originarias justificativas de la supresión. Recomendaba el conde que Carlos III escribiera a su primo y tratase el punto de la extinción, con el fin de acabar de determinar al monarca galo. Mas en esos momentos, es decir, reciente el extrañamiento de España y con el problema añadido de encontrar asilo a los expulsos repelidos de Civitavecchia, la resolución del rey Católico en este asunto tampoco era prioritaria. Lo que sí estuvo claro desde el principio fue la necesidad de unión de las cortes católicas; en palabras del embajador Pignatelli, «nuestros Soberanos deberían pensar seriamente unidos con las otras dos Ramas de la casa de Nápoles, y Parma, con el Rey de Portugal, y si fuese posible con la Emperatriz Reyna, como poseedora de los Estados de la Casa de Austria, y con el Emperador, en pedir al Papa la secularización, y total disolución de la Orden» ${ }^{65}$.

Las anexiones de Aviñón y Benevento hicieron que la curia vaticana empezara a tomar en consideración las amenazas de las Cortes. Desde París escribió el conde de Fuentes acerca de las ideas del nuncio allí establecido, quien le habló «sobre su pensamiento de secularización de la Orden de los Jesuitas, pero ni me ha mostrado el proyecto, ni he visto en sus discursos, sino especies vagas que me hacen creer no resultará nada que valga» ${ }^{66}$. Pero la voluntad de diálogo comenzaba a restañarse, aun-

63. A.G.S., Estado, leg. 4565, Grimaldi a Fuentes, 5 de diciembre de 1768.

64. Ibidem, París, 8 de mayo de 1767, Fuentes a Grimaldi.

65. Ibídem, París, 13 de mayo de 1767 , Fuentes a Grimaldi.

66. A.H.N., Estado, leg. 6559, Fuentes a Grimaldi, París, 27 de junio de 1768. 
que en una posición privilegiada por parte de los soberanos católicos, cosechada tras su ofensiva bélica contra los dominios papales mencionados. Entre las condiciones fijadas para entrar en composición con Roma, estaba «como una de las más principales, la de la extinción de los Jesuitas» ${ }^{67}$, aspecto preliminar e indispensable que dejó de serlo para continuar su fluir independiente de las satisfacciones al Monitorio, las cuales se retrasaban, según criterio de los fiscales del Consejo Extraordinario, por «el fanatismo de los Regulares expulsos [...], creyendo evitar conesta turbulencia la extinción de la Compañía, cuya existencia será siempre un estorbo de la verdadera reconciliación del Imperio y del Sacerdocio» ${ }^{68}$.

En el crepúsculo de 1768, la disposición de Francia «en quanto a la utilidad, y necesidad de hacer en Roma la solicitud de la extinción» era pareja a la de España, por lo «que se han dado las órdenes a Monsieur d'Aubeterre, no sólo de presentar la Memoria que se le remite (la qual en el fondo es lo mismo que la de nuestra Corte) sino que se le encarga de declarar que S.M. Christianísima [se] adhiere al mismo tiempo a la Memoria presentada por el Ministro del Rey su primo», una Memoria que no trataría los puntos de la doctrina y la moral «porque no conviene en Francia el dar el menor motivo a resucitar las antiguas disputas (hoy casi del todo olvidadas) sobre el probabilismo y otros asuntos, las quales han servido en los tiempos pasados de pretexto para turbar la tranquilidad del Reyno» ${ }^{69}$.

Clemente XIII fue aceptando los escritos representados por los embajadores de las Cortes destinados en la Santa Sede. El primero en ser recibido fue Tomás Azpuru, el 16 de enero de1769 $9^{70}$, siguiéndole el cardenal Orsini en nombre de Nápoles (día 20), y finalizando estas audiencias el marqués de Aubeterre (el 24) por parte de Francia. La deficiente salud del Santo Padre, conocida desde unos años atrás, había hecho recomendable la exposición de estas instancias, sobre todo con las miras puestas en un próximo cónclave donde resultaría cardinal que los congregados conociesen las pretensiones borbónicas. Esta premonición no tardó en cumplirse, pues el 2 de febrero ${ }^{71}$, a los 76 años de edad, el papa Rezzonico expiraba y ponía fin a un pontificado difícil, particularmente en la última etapa, abriéndose el período elector de un nuevo Vicario de Cristo.

El 5 de junio, esto es, un día después de la ceremonia de coronación del franciscano Lorenzo Ganganelli como Clemente XIV, ya se advirtió al conde de Fuentes que departiera con el ministro galo para transmitir al cardenal de Bernis las órdenes

67. A.G.S., Estado, leg. 4565, Fuentes a Grimaldi, París, 23 de septiembre de 1768.

68. A.G.S., Estado, leg. 5036, Consejo Extraordinario, 30 de noviembre de 1768.

69. A.G.S., Estado, leg. 4565 , Fuentes a Grimaldi, París, 30 de diciembre de 1768 . En este mismo legajo encontramos una carta de Choiseul a Fuentes, fechada el 27 de diciembre de ese año, donde le confirmaba al conde «que Sa Majesté lui prescrit [a Aubeterre] de remettre a Sa Santité ce mémoire en mème tempre que M. Azpuru éxécutera l'ordre de prescuter celui que Sa Majesté Catholique fera adresser a ce Ministre».

70. A.H.N., Estado, leg. 6566, Azpuru a Fuentes, Roma, 18 de enero de 1769.

71. A.H.N., Estado, leg. 6560, Azpuru a Fuentes, Roma, 5 de febrero de 1769. 
dirigidas a renovar, en inteligencia con Orsini y Azpuru, la solicitud de extinción ${ }^{72}$. Tras el cónclave, al prelado francés se le designó titular de la embajada de su nación cabe la Santa Sede, desplazando al marqués de Aubeterre. Bernis atribuyó al comportamiento de Francia en las deliberaciones de la convención cardenalicia la designación de Lorenzo Ganganelli, algo incierto ${ }^{73}$. Veraz, en cambio, resulta la afirmación de que Bernis, al igual que Choiseul, colocó en segundo término la cuestión de la supresión jesuítica. Prueba de ello fue la demora en la recepción, por parte del purpurado francés, del aludido mandamiento a proceder junto a los otros dos clérigos que, como él, desempeñaban funciones diplomáticas en favor de España y Nápoles. «Nos mantenemos -instruyó Grimaldi al embajador Pignatelli- siempre en expectación favorable por lo que toca al nuevo Papa. Sigue teniendo las condescendencias particulares que se ofrecen, pero no se le ha provocado en los grandes negocios, aunque muestra igual buena voluntad. El de la extinción de los Jesuitas, que es el primero, no se ha empezado por que falta el que llegue al Ministro de Francia en Roma la orden de pedirla formalmente en comunidad con los de España y Nápoles, pero a estas oras suponemos que ya le avrá llegado» ${ }^{74}$.

En efecto, el 10 de julio remitió Fuentes una carta a su superior en la que especificaba como Choiseul «me ha dicho [...], que en las instrucciones que se le dieron al Cardenal de Bernis se le prevenía particularmente continuase en solicitar con el nuevo Papa la extinción de la Compañía, de acuerdo con el Ministro de España y de Nápoles», añadiendo el duque, además, «que el Cardenal de Bernis había hablado al Papa antes de su elección sobre este mismo negocio, y aún hechole ver una Memoria relativa a él; que también le había tocado el asunto luego después de elegido» ${ }^{75}$.

Pero Clemente XIV dilataba en la medida de sus posibilidades la disolución de la Compañía, algo que inevitablemente apreciaban los gobiernos borbónicos: « [...] me ha dicho el duque de Choiseul, si tal vez podría convenir, vista la timidez del Papa, y su carácter débil, que hará tal vez que no se resuelva el partido pronto que deseamos, el preparar la abolición paso a paso [...]. Aquí no se tendrá otro lenguage, ni se hará cosa, que lo que el Rey nuestro Señor resolviesse» ${ }^{76}$. Revelador documento en el que se empieza a columbrar la no conclusión inmediata del proyecto, así como el papel director de España al que se acomodarían el resto de las naciones.

Si el año de 1770 pareció comenzar con buenas perspectivas, fruto de la misiva enviada por el pontífice al soberano español ${ }^{n}$, la realidad no secundó esas fundadas esperanzas de hallar una inmediata solución al conflicto jesuítico. Los trastornos de

72. A.G.S., Estado, leg. 5036, Grimaldi a Fuentes, Aranjuez, 14 de junio de 1769.

73. PINEDO, I y ZABALA, A., «Bernis y Floridablanca: dos diplomáticos de la Ilustración en la campaña de extinción de los jesuitas (1769-1773), Estudios de Geografía e Historia (Deusto), 1988, pp. 523-536.

74. A.G.S., Estado, leg. 4569, Grimaldi a Fuentes, Madrid, 7 de julio de 1769.

75. Ibídem, París, 10 de julio de 1769, Fuentes a Grimaldi.

76. A.G.S., Estado, leg. 4569, Grimaldi a Fuentes, San Ildefonso, 14 de agosto de 1769.

77. Ganganelli escribió al rey hispano asegurando su inclinación a condescender a la abolición de la Religión jesuítica. Carlos III replicó en carta fechada el 26 de diciembre de 1769; en A.G.S., Estado, leg. 5036 , Grimaldi a Fuentes, $1^{\circ}$ de enero de 1770. 
salud del diplomático y clérigo aragonés Tomás Azpuru, las estancias del pontífice en la campiña, los matices y revisiones de un breve de aprobación que nunca satisfacía a la curia romana; incluso, las convulsiones de la política internacional -léase conflicto hispano-británico por las islas Malvinas ${ }^{78}$, o la caída del ministro Choiseul-, fueron elementos empleados por Lorenzo Ganganelli en su estrategia dilatora. De este último punto, es decir, de la destitución del mandatario francés, elaboró Joaquín Pignatelli una extensa relación fechada el 29 de diciembre de 1770. En ella aprovechaba para guarecer su reputación, comentándole a Luis XV que «había sentido mucho lo sucedido por la amistad que le profesaba [a Choiseul], pero que no dudaba S.M. estaría bien persuadido que mi amistad no habría podido de ninguna manera producir en el Duque la menor idea que tubiesse conexión con los motivos del desagrado a que me decía S.M. haber dado lugar a su conducta» ${ }^{79}$. Según Joaquín Pignatelli, el nombre del duque de Aiguillon era el que más se oía para acceder al cargo vacante, y «si se verifica esta elección es lo peor que nos pudiera suceder ${ }^{80}$. Refirió el conde, asimismo, su desconfianza en el avance del plan común hacia la supresión del Instituto ignaciano, porque «es indubitable que el punto de la extinción dela Compañia, ya no tendrá más movimiento, ni otro impulso que el que el Rey nuestro Señor le diese» ${ }^{81}$.

El panorama político pincelado por Fuentes poseía unos rasgos decadentes, caldo de cultivo de la posterior revolución: el rey, entregado al ocio y al lujo, rodeado de un colectivo que el embajador Pignatelli caracterizaba de projesuita; el Parlamento, único órgano capaz de presentar batalla a la omnipotencia real, suprimido por la ofensiva de Maupeau ${ }^{82}$, configurándose otro más displicente. La alarma del conde de Fuentes fue en aumento, pues «una buena parte de los que componen el nuevo Parlamento son partidarios de los Jesuitas» ${ }^{83}$.

El 24 de junio de 1771, Pignatelli escribió con claridad y firmeza a Jerónimo Grimaldi -una claridad e intensidad explicadas por la incomodidad del embajador después de la exoneración de su amigo Choiseul-, narrándole la degeneración política y humana de la corte de Versalles, añorando la época en la que el duque regía los destinos galos. Según el conde, «la Corte se va envileciendo más cada día y este contagio va pasando a la capital y a la Nación [...], de manera que una Nación noble y elevada se convertirá en baja y abatida (sino hay antes alguna revolución extraordinaria) y mudará su carácter natural». No es de extrañar, tampoco, el concepto del

78. España ocupaba desde 1767 la isla oriental o de la Soledad. En la isla occidental o Gran Malvina, el inglés Byron había fundado la factoría de Port Egmont en 1765. Los españoles obligaron a capitular a la factoría inglesa (1770), pero poco después la devolvieron a la Gran Bretaña con la promesa de ésta de abandonarla en el futuro, cosa que hizo en 1774.

79. A.G.S., Estado, leg. 4577, Fuentes a Grimaldi, París, 29 de diciembre de 1770.

80. Id., Fuentes a Grimaldi, París, 10 de enero de 1771.

81. A.H.N., Estado, leg. 3518, Fuentes a Grimaldi, París, 28 de febrero de 1771.

82. Maupeau había presidido el Parlamento en 1766. Dos años después fue nombrado canciller. Su política autoritaria le granjeó enemigos en todos los estamentos, siendo sustituido al subir Luis XVI al trono, en 1774.

83. A.G.S., Estado, leg. 4578, Fuentes a Grimaldi, París, 2 de mayo de 1771. 
embajador sobre el duque de Aiguillon, nombrado en esas fechas para comandar las labores anteriormente atribuidas a Choiseul: «lo menos que se puede decir de él -sentenciaba Fuentes- es que es de un genio y natural vengativo; que su reputación es mui dudosa; que tiene mui fuertes y irreconciliables enemigos [...], su único apoyo para lograr el ministerio ha sido Madame du Barry». Así, el aragonés recomendaba andar con tiento y precaución en el trato con el nuevo gabinete francés, siendo los hechos concretos los facultados para asentar la confianza, «particularmente en los asuntos de Roma, de Parma y de los Jesuitas» ${ }^{84}$.

El conde de Fuentes confesaba su disposición a concluir el plan secularizador. «Yo -detalló a Grimaldi- por mi parte no pierdo ocasión de hacer ver a este Ministro [Aiguillon] la importancia de lograr èl empeño, las veras con que el Rey nuestro Señor lo desea y los inconvenientes y males que se evitarán si se logra», así como proponía medios contundentes si el papa persistía en su retraso, medidas tendentes a hacer «justicia y para cortar los muchos abusos que reynan en las mismas materias [jurisdiccionales, presencia de eclesiásticos y regulares, nunciatura] en que mantiene aquella Corte [Roma] su potestad y de que saca muchas ventajas temporales» ${ }^{85}$.

La renuncia por enfermedad de Tomás Azpuru a la embajada de Roma, y la elección del conde de Lavaña para sustituirlo, fue acogida por Fuentes con satisfacción, entendiendo que con un laico las instancias de supresión se renovarían eficazmente. De ningún modo le admiraba «la lentitud del Cardenal de Bernis, y de qualquiera otro Eclesiástico en estas Negociaciones», pues no es posible «hacer bien el servicio a dos Amos que tienen principios y intereses opuestos» ${ }^{86}$. Pero Lavaña, en el tránsito a Roma, sufrió un ataque apopléjico que acabó con su vida el 23 de febrero de 1772. El óbito del conde sirvió al pontífice para seguir postergando su decisión y tranquilizarse un poco, pues «las instancias que suponían haría el Conde de Lavaña, serían más vigorosas que hasta aquí; y por esta misma razón dice el Duque de Aiguillon que importa infinito que su sucesor sea hombre de firmeza, de habilidad, y de desempeño». Creyó Fuentes llegado el momento, en el «grave asunto de extinción de la Compañia», de tomar uno de los dos partidos que él mismo proponía: «el de no hablar por ahora más de ella, o el de pedirla de modo que se haga temer a Roma, y que se efectúe». Si el gobierno hispano se inclinase por la primera opción, no se debería ceder a ninguna propuesta de reforma, dejando en suspenso la solicitud de abolición; si se elegía la segunda, la acción tendría que ser contundente, disponiendo «algunos Regimientos de Dragones prontos para entrar en Castro y Ronciglione [...]. Esta determinación haría ver al Papa, y a Roma que la cosa iba de veras, y que de nada servian los Capelos con que hasta aqui ha ido ganando tiempo, ni el haber engañado antes y después de su elevación al Pontificado a los primeros Príncipes de la

84. A.H.N., Estado, leg. 3518, Fuentes a Grimaldi, París, 24 de junio de 1771. La «negrita» es nuestra.

85. Id., Fuentes a Grimaldi, Fontainebleau, 26 de octubre de 1771. Estas celosas indicaciones de Pignatelli motivaron una carta del P. Ricci, general de la Orden, al P. José Pignatelli, lamentando los esfuerzos del conde para abolir la Compañía; en MARCH, J.M., El Restaurador..., t. I., pp. 303-304.

86. A.G.S., Estado, leg. 4584, Fuentes a Grimaldi, París, 9 de marzo de 1772. 
Christiandad ${ }^{87}$. La ira del conde de Fuentes se inscribía dentro de una espiral ascendente.

El 24 de marzo se conoció la elección de José Moñino como embajador en Roma, y el marqués de Grimaldi remitió al conde las cualidades del nuevo embajador, al que calificó de «mozo sumamente instruido en todas materias; pero con particularidad, y no sólo por teórico sino por práctica, en aquellas que pueden tratarse en la referida Corte o tener conexión con la extinción de la Compañía y con las prerrogativas dela Soberanía temporal. Es seglar, de bellos modales y de loables costumbres, y su carácter insinuante modesto y prudente, pero mui activo: y casi el más a propósito que podría hallarse para el estado actual de los negocios» ${ }^{88}$.

El futuro conde de Floridablanca tenía que estimular un proceso en el que la curia vaticana recurrió a tácticas y excusas contemporizadoras desde los primeros días del pontificado de Clemente XIV y que habían despertado el espíritu belicista del embajador Pignatelli. Éste proponía, después de «más de tres años de moderación de nuestra parte», que «no se conseguirá la extinción sin uno de estos dos medios: el primero la ocupación de Castro [...]: el segundo el que nuestra Corte haga entender al Papa, que no cumpliendo Su Santidad lo que ha ofrecido no solamente publicará la negociación con Roma, sino también las cartas de Su Santidad al Rey nuestro Señor aprobando S.M. quanto egecutó en sus Estados con los Jesuitas» ${ }^{89}$.

La inflexibilidad del fiscal murciano determinaron que, en audiencia del 29 de noviembre, Clemente XIV le comunicase su decisión de extinguir la Compañía. Cuando ésta ocurrió (el breve Dominus ac Redemptor fue signado el 21 de julio de 1773) hacía casi un año que el conde de Fuentes había retornado a España. Debemos encontrar en la destitución del duque de Choiseul un factor añadido a su descontento por su permanencia en la embajada parisina: «el conde de Fuentes [...] mostraba deseo de retirarse, y suplicaba se le relevara ${ }^{90}$, aunque, a juicio de Tanucci, Joaquín Pignatelli nunca se halló cómodo en su puesto. Desde Portici, el ministro napolitano escribió a Esquilache a raíz de los trastornos que padeció el aragonés en el otoño de 1764: «Chi crederebbe che non fosse nella gran Monarchia soggetto che rimpiazzi il conte de Fuentes nell'ambasciata di Francia? Egli veramente in Francia non sta bene» ${ }^{91}$. Es cierto que con la partida de Choiseul del ministerio galo se agudizó el descontento de Fuentes, algo que hemos comprobado en las extensas relaciones que remitió a Jerónimo Grimaldi acerca de la degeneración y corrupción de la corte de Versalles. A la par, se observa en sus palabras un ardor y una energía nacidas de su malestar personal, que proyecta sobre el negocio de la extinción participando soluciones expeditivas para la obtención de un final acorde con las aspiraciones borbónicas..., y con las suyas propias.

87. A.G.S., Estado, leg. 5038, Fuentes a Grimaldi, París, 25 de marzo de 1772.

88. Ibidem, Madrid, 28 de abril de 1772 , Grimaldi a Fuentes.

89. A.G.S., Estado, leg. 5039, Fuentes a Grimaldi, París, 26 de junio de 1772.

90. DANVILA Y COLLADO, M., Op. Cit., t. III, p. 272.

91. TANUCCI, B., Epistolario, vol. XIV, 1995, p. 349. Portici, 13 de noviembre de 1764, a Squillace. 